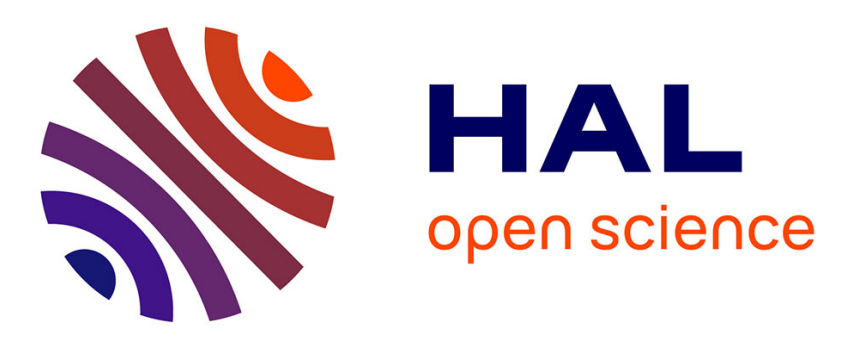

\title{
Interaction between the Voltage-Droop and the Frequency-Droop Control for Multi-Terminal HVDC Systems
}

Samy Akkari, Marc Petit, Jing Dai, Xavier Guillaud

\section{- To cite this version:}

Samy Akkari, Marc Petit, Jing Dai, Xavier Guillaud. Interaction between the Voltage-Droop and the Frequency-Droop Control for Multi-Terminal HVDC Systems. AC and DC Power Transmission, 11th IET International Conference on, Feb 2015, Birmingham, United Kingdom. 10.1049/cp.2015.0036 . hal-01243994

\section{HAL Id: hal-01243994 \\ https://hal-centralesupelec.archives-ouvertes.fr/hal-01243994}

Submitted on 15 Dec 2015

HAL is a multi-disciplinary open access archive for the deposit and dissemination of scientific research documents, whether they are published or not. The documents may come from teaching and research institutions in France or abroad, or from public or private research centers.
L'archive ouverte pluridisciplinaire HAL, est destinée au dépôt et à la diffusion de documents scientifiques de niveau recherche, publiés ou non, émanant des établissements d'enseignement et de recherche français ou étrangers, des laboratoires publics ou privés. 


\title{
Interaction between the Voltage-Droop and the Frequency-Droop Control for Multi-Terminal HVDC Systems
}

\author{
S Akkari*, M Petit*, J Dai*, X Guillaud ${ }^{\dagger}$ \\ *Supélec, France, Département Énergie, Plateau de Moulon, 3 rue Joliot Curie, 91192 Gif-sur-Yvette \\ samy.akkari@supelec.fr, jing.dai@supelec.fr, marc.petit@supelec.fr \\ ${ }^{\dagger}$ L2EP, France, École Centrale de Lille - Cité Scientifique, BP 4859651 Villeneuve d'Ascq \\ xavier.guillaud@ec-lille.fr
}

Keywords: HVDC, grids, MTDC, voltage droop, frequency droop.

\begin{abstract}
MTDC systems need to provide a high level of reliability as well as efficient support to the interconnected AC grids. This can be achieved by equipping each converter with a dual controller combining both the voltage-droop and the frequency-droop control techniques. In this article, the theory behind the coupling between the two droops is investigated and an electromagnetic transient study of a 5-terminal HVDC grid is discussed to validate the theoretical results. The use of the dual controller allows the whole system to be more flexible. However, the frequency droop coefficient must be corrected to comply with the TSO's requirements.
\end{abstract}

\section{Introduction}

The ever growing installed capacity of offshore wind farms is pushing coastal nations to develop the Multi-Terminal HVDC (MTDC) technology, which is admittedly the most feasible solution to connecting the wind farms to onshore grids and interconnecting asynchronous AC systems [1, 2]. However, the master-slave control technique used to operate the existing HVDC links is not suitable for meshed HVDC grids. The voltage-droop control technique, depicted in [3, 4, 5], seems to be the best solution to safely and efficiently controlling MTDC systems.

As the use of renewable energy sources increases, their participation in the onshore grids frequency regulation is under consideration, especially given the fact that polluting conventional generation units participating in frequency regulation are gradually shut down and replaced by green energy sources such as offshore wind farms in order to reduce greenhouse gas emissions. There arises the necessity to develop a new control technique that would allow the AC/DC converters of the HVDC grid to participate in the primary frequency regulation of the $\mathrm{AC}$ systems. This can be achieved through the power electronics of the converters by using a frequency-droop controller based on the same principle as the frequency regulation controllers used in conventional generation units in $\mathrm{AC}$ grids $[6,7,8]$. The injected/withdrawn power of the converter into/from the $\mathrm{AC}$ grid should correspond to a precise value with regards to the frequency deviation of the grid, and must comply with the AC grid Transmission System Operator (TSO)'s requirements.

This paper considers a control strategy that combines both the voltage-droop and the frequency-droop control techniques for a Voltage Source Converter (VSC) HVDC. This dual control technique helps stabilizing the DC grid thanks to the DC voltage droop and allows the MTDC system to participate in the frequency regulation of the different $\mathrm{AC}$ grids interconnected by the meshed HVDC grid thanks to the frequency droop.

Only a few papers used the two droop control techniques at the same time on a single VSC-HVDC converter. While [8] focuses on the eigenvalues of the system and [9] describes the use of a dead-band control for both droops, those two papers do not discuss interactions between the two droops. Without going into further details, [6] reports that the frequency droop does not give the desired value for a given frequency deviation. [7] is the only paper that really tried to understand the interactions between the AC grids and the DC grid through a modal analysis, whose conclusion was that the use of both droops resulted in a modification of the DC voltage dynamics and small changes in frequency.

This article points out the coupling between the two droops of the dual controller. The interactions between the frequency droop and the voltage droop are mathematically quantified in order to properly choose the slopes of the droops allowing the system to behave as expected. Then a simulation using the software EMTP-RV is run to validate the theoretical study.

The paper is outlined as follows. First, the principle of the voltage-droop and the frequency-droop control techniques as well as the functioning of the dual controller are discussed in Section 2. In Section 3, a theoretical analysis of the coupling between the two droops is conducted. Finally in Section 4, a simulation validating the theoretical study illustrates the behaviour of a 5-terminal MTDC system, which interconnects two offshore wind farms and three asynchronous AC grids, after an AC fault. Conclusions are drawn in Section 5. 


\section{Combining the voltage-droop and the frequency-droop control techniques}

This section briefly explains the functioning principle of both the voltage-droop and the frequency-droop control. Then, it considers a control strategy combining the advantages of the two control techniques.

Droop-based control techniques directly modify the power reference of the converter. Figure 1 shows the global command strategy of a VSC-HVDC converter.

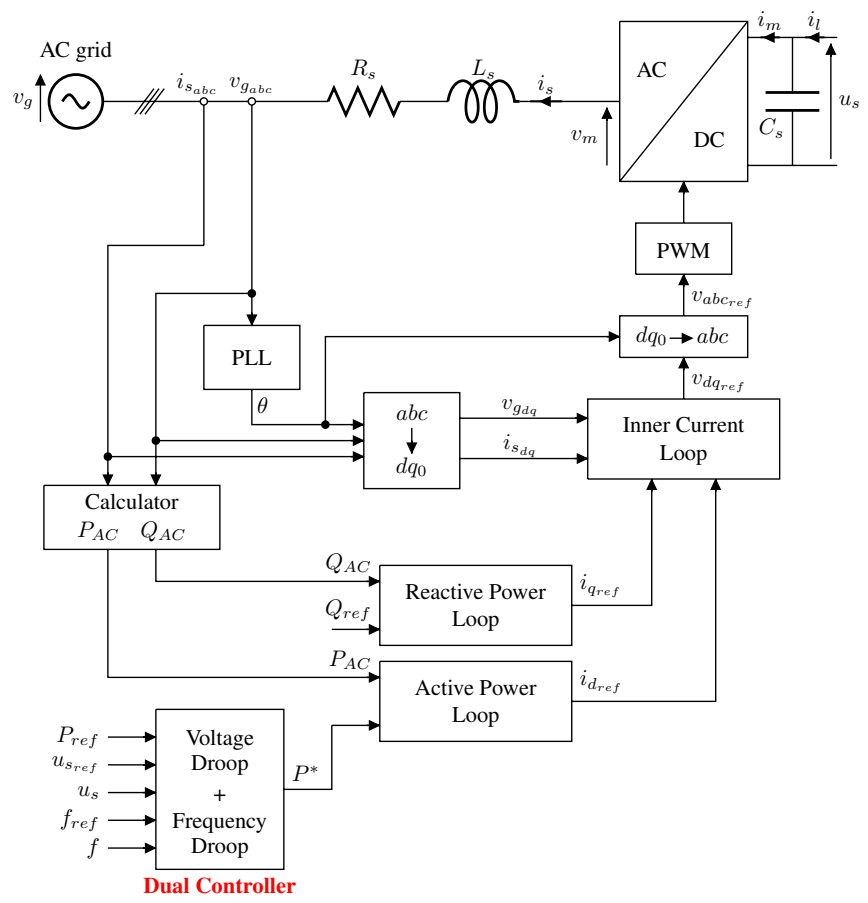

Fig. 1: Control strategy of a VSC-HVDC converter

In this section, the $i^{\text {th }}$ converter of a $n$-converter MTDC system is considered.

\subsection{The voltage-droop control technique}

The basic principle of the voltage-droop control is as follows. If a DC voltage variation is detected by a converter equipped with a voltage droop, this controller will generate a linear deviation of the power reference of the converter that helps stabilizing the MTDC system by balancing the power on the DC grid, thus preventing the DC voltage from dropping to critical levels.

The literature furnishes several methods of voltage-droop control. The one described in $[3,5,10]$ seems to be the best feasible solution thanks to its simplicity and efficiency.

A converter equipped with a voltage-droop control technique modifies its power reference according to the DC voltage level by moving its operating point along the characteristic line whose slope is $\frac{1}{k_{v}}$, where $k_{v}$ is the voltage-droop parameter, as depicted in (1).

$$
\Delta P_{v_{i}}^{*}=\frac{1}{k_{v_{i}}} \Delta u_{s_{i}}
$$

where:

- $\Delta P_{i}^{*}$ is the total power reference deviation of the $i^{\text {th }}$ VSCHVDC converter. A positive $P_{i}$ corresponds to a power injection from the DC grid to the AC grid.

- $k_{v_{i}}$ is the voltage-droop parameter of the $i^{\text {th }}$ converter, $k_{v_{i}}<0$.

- $\Delta u_{s_{i}}$ is the DC voltage variation at the $i^{\text {th }}$ converter terminal with regard to its voltage reference: $\Delta u_{s_{i}}=u_{s_{i_{r e f}}}-u_{s_{i}}$.

Each controller is also equipped with limiters that prevent the converter from moving too far away from its original operating point.

The block diagram of the voltage-droop control technique is depicted in Figure 2.

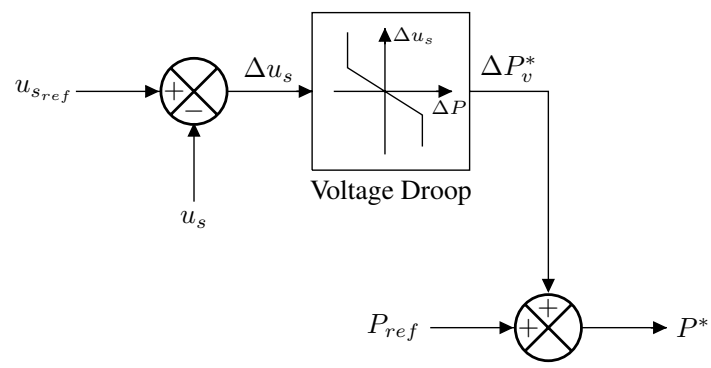

Fig. 2: Block diagram of the voltage-droop technique

\subsection{The frequency-droop control technique}

The primary frequency control is currently used by conventional generation units in $\mathrm{AC}$ grids. If the frequency drops below (respectively rises above) its nominal value, the conventional units inject more (resp. less) power into the AC grid in order to stabilize the frequency of the system.

The frequency droops proposed in $[6,7,8]$ are similar although there are some differences within the global control of the VSC-HVDC (see Figure 1 for the global control of the converter used in this paper).

The solution adopted in the present paper is the same as [7]. Its operating principle is very similar to the one of the voltage droop of Section 2.1. A converter equipped with a frequencydroop control participates in the frequency regulation of the AC grid it is connected to and modifies its power reference by following the characteristic line whose slope is $\frac{1}{k_{f}}$, where $k_{f}$ is to the frequency-droop parameter:

$$
\Delta P_{f_{i}}^{*}=\frac{1}{k_{f_{i}}} \Delta f_{i}
$$

where: 
- $k_{f_{i}}$ is the frequency-droop parameter of the $i^{\text {th }}$ converter, $k_{f_{i}}>0$.

- $\Delta f_{i}$ is the frequency variation of the AC grid connected to the $i^{\text {th }}$ converter with regard to its frequency reference: $\Delta f_{i}=f_{i_{r e f}}-f_{i}$.

Each controller is also equipped with limiters that prevent the converter from moving too far away from its original operating point.

The block diagram of the voltage-droop control technique is depicted in Figure 3.

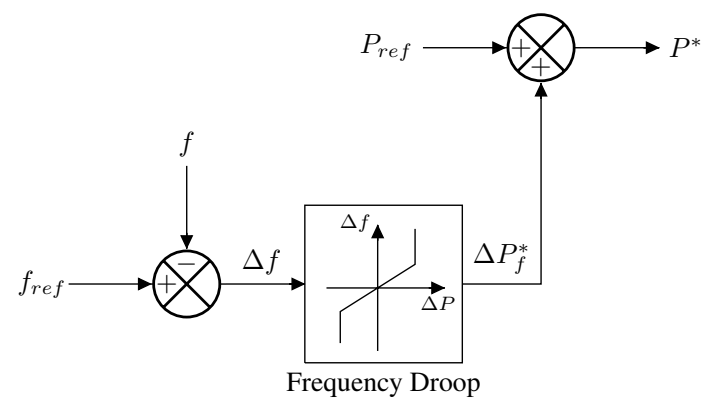

Fig. 3: Block diagram of the frequency-droop technique

\subsection{The dual control technique}

The voltage-droop control technique provides a strong and reliable DC grid, while the frequency-droop control technique provides assistance to the interconnected AC grids. An ideal MTDC system should have both : a strong and reliable DC grid as well as a good support to the interconnected AC grids.

The combination of those two control techniques leads to a dual controller depicted in Figure 4. This dual controller holds both the advantages of the frequency-droop control technique and the voltage-droop control technique. However, the combination of the two droops also leads to undesirable side-effects which will be further discussed in Section 3.

With this dual controller the converter's operating point does not move along a single line any longer but obeys (3).

$$
\begin{aligned}
\Delta P_{i}^{*} & =\Delta P_{v_{i}}^{*}+\Delta P_{f_{i}}^{*} \\
& =\frac{1}{k_{v_{i}}} \Delta u_{s_{i}}+\frac{1}{k_{f_{i}}} \Delta f_{i}
\end{aligned}
$$

\section{Interactions between the two droops}

This section points out the existing coupling between the two droops used by the dual controller presented in Subsection 2.3 and theoretically quantifies their interactions.

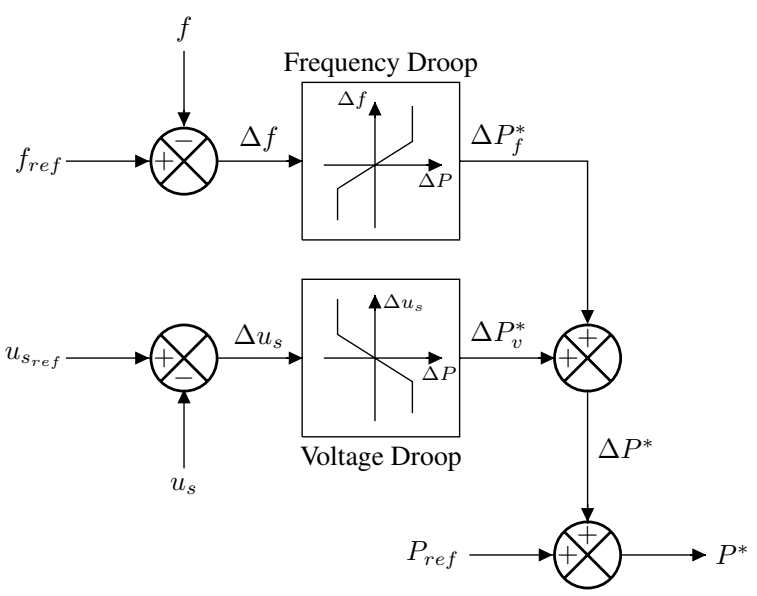

Fig. 4: Block diagram of the dual controller

\subsection{The dual nature of the controller}

As stated in Section 2.3, the dual controller offers the advantages of both the voltage-droop and the frequency-droop control techniques.

However, there is a coupling between the two droops. For example, if the DC voltage decreases (resp. increases), the voltage droop modifies the amount of power injected/withdrawn by the converter so that there is either less (resp. more) power withdrawn from the DC grid or more (resp. less) power injected into the DC grid. This, in turn, decreases (resp. increases) the frequency of the AC grid connected to the converter and the frequency droop opposes the action of the voltage droop, resulting in interactions between the $\mathrm{AC}$ grids and the $\mathrm{DC}$ grid.

This coupling is problematic since it degrades the performances of both the voltage droop and the frequency droop of the converter equipped with the dual controller. However, when the $\mathrm{AC}$ grid needs frequency support, priority should be given to the frequency droop since the TSO of the concerned AC grid expects a rigorous value of the frequency droop for the VSCHVDC converter. This means the impact of the voltage droop on the frequency droop must be quantified and the frequency droop parameter must be corrected in order to comply with the TSO's requirements. The impact of the frequency droop on the voltage droop also needs to be quantified in order to be taken into account when managing the DC grid.

\subsection{Theoretical study on the impact of the voltage droop on the frequency droop}

The following theoretical study gives the direct relation between the frequency deviation of the grid and the power deviation of the converter.

In order to simplify the equations, the following simplifying assumption is made:

- DC voltage variations are identical at all nodes of the HVDC 
grid. This is equivalent to neglecting the variation of the sum of power losses in the DC grid.

Hence, if we consider an MTDC system with $n$ converters:

$$
\forall j \in\{1, \ldots, n\}, \quad \Delta u_{s_{j}}=\Delta u_{s}
$$

After an AC event such as the loss of a generation unit or a load modification, in steady state, the effective power deviation of each one of the $n$ converters obeys the power reference deviation of (3), which gives (5):

$$
\forall j \in\{1, \ldots, n\}, \quad \Delta P_{j}=\frac{1}{k_{v_{j}}} \Delta u_{s}+\frac{1}{k_{f_{j}}} \Delta f_{j}
$$

Note: Equation (5) gives a general expression of the power deviation of each VSC-HVDC converter. If the considered converter $j$ is not equipped with a voltage-droop controller then $k_{v_{j}}=-\infty \mathrm{kV} / \mathrm{MW}$. If the considered converter $j$ is not equipped with a frequency-droop controller then $k_{f_{j}}=\infty$ Hz/MW.

The sum of the $n$ equations (5) gives :

$$
\sum_{j=1}^{n} \Delta P_{j}=\sum_{j=1}^{n} \frac{1}{k_{v_{j}}} \Delta u_{s}+\sum_{j=1}^{n} \frac{1}{k_{f_{j}}} \Delta f_{j}
$$

Since the variation of the sum of power losses is neglected and since the power on the DC grid is balanced by the converters equipped with a voltage droop, $\sum_{j=1}^{n} \Delta P_{j}=0$.

Thus (6) becomes:

$$
\sum_{j=1}^{n} \frac{1}{k_{v_{j}}} \Delta u_{s}=-\sum_{j=1}^{n} \frac{1}{k_{f_{j}}} \Delta f_{j}
$$

and since $\Delta u_{s}$ is considered identical for all VSC-HVDC converters, (7) leads to a new expression of $\Delta u_{s}$ :

$$
\Delta u_{s}=\frac{-1}{\sum_{j=1}^{n} \frac{1}{k_{v_{j}}}} \sum_{j=1}^{n} \frac{1}{k_{f_{j}}} \Delta f_{j}
$$

Let us now consider the $i^{\text {th }}$ converter of the MTDC system. Replacing $\Delta u_{s}$ in (5) by (8) yields:

$$
\Delta P_{i}=\frac{-1}{k_{v_{i}} \sum_{j=1}^{n} \frac{1}{k_{v_{j}}}}\left(\sum_{j=1}^{n} \frac{1}{k_{f_{j}}} \Delta f_{j}\right)+\frac{1}{k_{f_{i}}} \Delta f_{i}
$$

Equation (9) shows that the power deviation of the $i^{\text {th }}$ converter consists of:

$\triangleright$ The power deviation created by the sum of the frequency droops of every converter on the DC grid weighted by $\frac{-1}{k_{v_{i}} \sum_{j=1}^{n} \frac{1}{k_{v_{j}}}}$. This coefficient depends on the action of the voltage droop of the $i^{\text {th }}$ converter and also depends on the contribution (voltage-droop parameters $k_{v_{j}}$ ) of each converter participating in the DC voltage regulation. $\triangleright$ The power deviation created by the frequency droop of the $i^{\text {th }}$ converter.

Since the maximum power deviation of an AC/DC converter is limited and since the total power transmitted through a converter is usually small in regard to the AC grid total active power, then if there is no $\mathrm{AC}$ fault happening at the same time on the other AC grids, $\Delta f_{j}$ for $j \neq i$ are negligible and (9) becomes:

$$
\Delta P_{i}=\frac{1}{k_{f_{i}}}\left(1-\frac{1}{k_{v_{i}} \sum_{j=1}^{n} \frac{1}{k_{v_{j}}}}\right) \Delta f_{i}
$$

This means that the actual relation between the AC grid frequency and the converter connected to this grid is now described by (10) and not by (2) anymore. In order to honour the announced frequency droop of the converter to the TSO in (2) in spite of the interaction between the voltage droop and the frequency droop, the frequency droop parameter $k_{f}$ of (10) must be corrected.

\section{Case study}

This section illustrates the behaviour of a 5-terminal MTDC system similar to the one used in [11] that interconnects two offshore wind farms and three asynchronous AC grids after a disturbance. Simulations are run with the electromagnetic transients program $E M T P-R V$. The DC grid includes six DC lines, as depicted in Figure 5. The very simplistic AC grid 1 used in this simulation is also depicted in Figure 5. All grid parameters are listed in Appendix.

\subsection{Considered system}

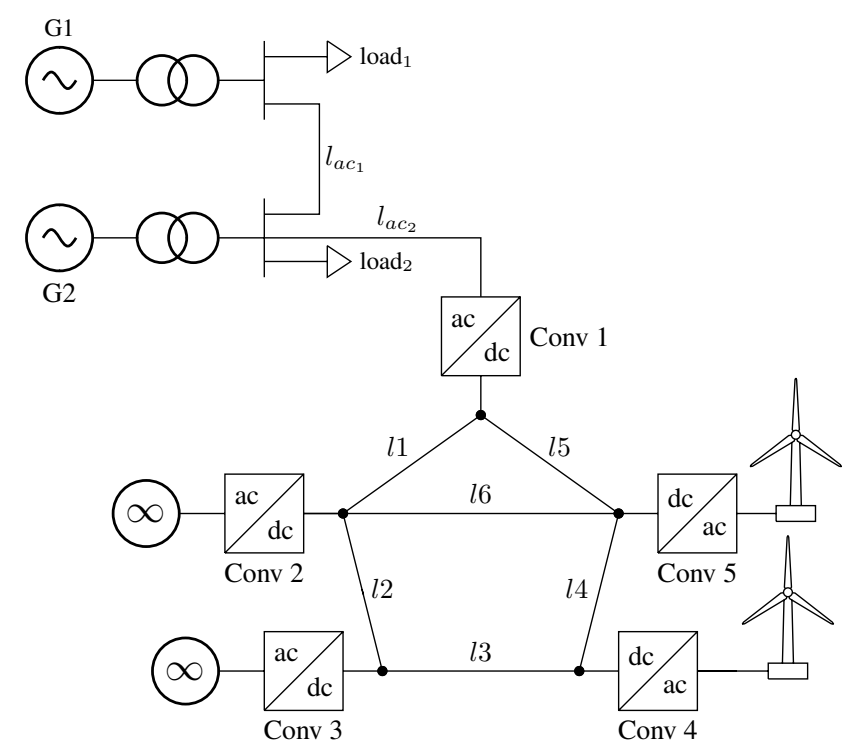

Fig. 5: Single-line diagram of the studied 5-terminal MTDC system and the AC grid 1 
In this section, only the VSC-HVDC converter 1 is equipped with the dual controller, meaning only the frequency of the $\mathrm{AC}$ grid 1 is supported by the MTDC system.

Converters 2 and 3 are only equipped with a voltage-droop controller, meaning they participate in the DC voltage regulation (along with converter 1) but they do not support the frequency regulation of their AC grids.

Converters 4 and 5 are offshore converters and are connected to wind farms. Since the time lapse of this study is small (about 30 seconds), the power output of the wind farms can be supposed constant. Converters 4 and 5 always inject into the DC grid the maximum output power of the wind farms. For this reason they are equipped with neither a frequency-droop controller nor a voltage-droop controller.

The modelling and the control of the VSC-HVDC converters is depicted in Figure 1.

The initial power reference of each VSC-HVDC converter as well as their droop coefficients are shown in Table 1.

\begin{tabular}{|c|c|c|c|c|c|}
\hline Converter & $\mathbf{1}$ & $\mathbf{2}$ & $\mathbf{3}$ & $\mathbf{4}$ & $\mathbf{5}$ \\
\hline$P_{\text {ref }}(\mathrm{MW})$ & 150 & 200 & -50 & -100 & -200 \\
\hline$k_{v}(\mathrm{kV} / \mathrm{MW})$ & -0.2 & -0.2 & -0.2 & $-\infty$ & $-\infty$ \\
\hline$k_{f}(\mathrm{~Hz} / \mathrm{MW})$ & 0.005 & $\infty$ & $\infty$ & $\infty$ & $\infty$ \\
\hline
\end{tabular}

Table 1: Power reference values and droop coefficients of the VSC-HVDC converters

\subsection{Case of an AC generation unit loss}

In this simulation, the AC grid 1 loses a generating station of $100 \mathrm{MW}$ at $t=3 \mathrm{~s}$ (generator 2 of Figure 5 ).

\subsubsection{Interaction between the frequency droop and the voltage droop}

Figure 6 shows the converter 1's power reference modification due to the voltage droop and the frequency droop. Since more power is withdrawn from the DC grid and injected into the AC grid 1 due to the activation of the frequency-droop controller, the DC voltage drops as well, which activates the voltage droop of the dual controller. The power deviation created by the voltage droop is caused by this interaction between the AC and the DC grid and hampers the frequency droop, preventing it from functioning at its full efficiency.

Figure 7 and Figure 8 respectively show the voltage of the $\mathrm{DC}$ grid and the frequency of the AC grid 1 in three different scenarios with regards to the dual controller of the converter 1 :

- The voltage-droop controller is activated but the frequencydroop controller is not activated (dashed curve).

- The voltage-droop controller is not activated but the frequency-droop controller is activated (dashdotted curve).

- The dual controller is fully activated (solid curve).

Figure 7 shows that the DC voltage remains the same when the frequency-droop controller is deactivated (dashed curve): the

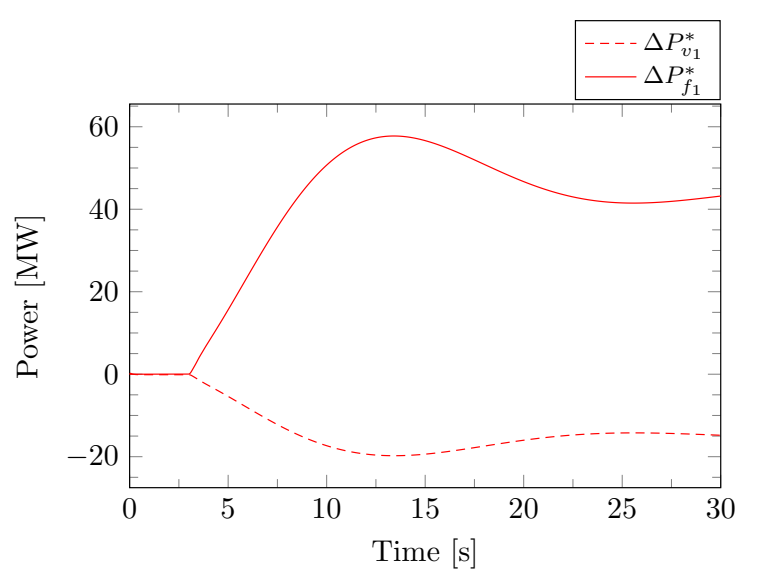

Fig. 6: Power reference modification due to the voltage droop and the frequency droop

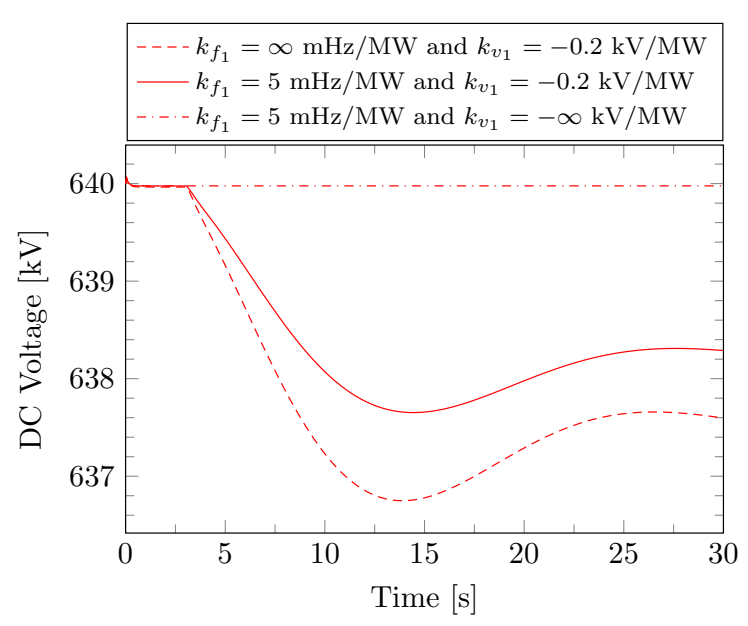

Fig. 7: DC Voltage at the converter 1 terminal

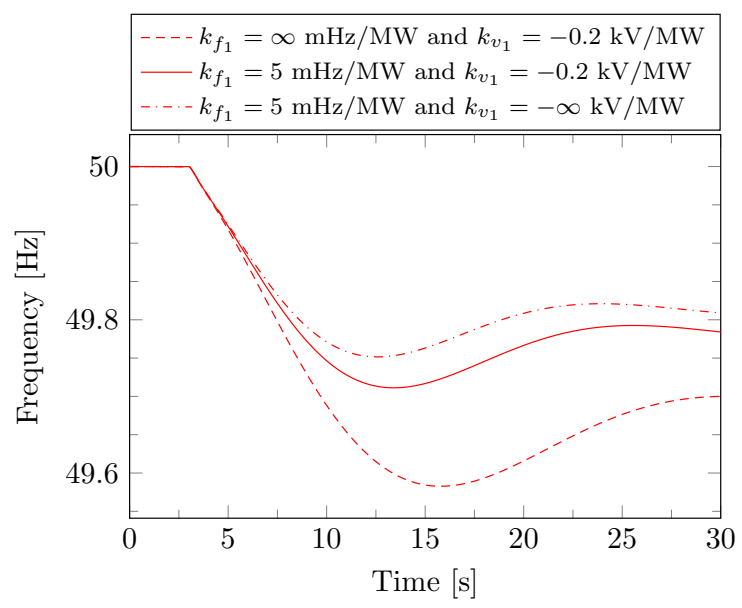

Fig. 8: Frequency of the AC grid 1 
DC grid does not participate in the frequency regulation of AC grid 1 . When the dual controller is fully activated (solid curve), the DC voltage does not drop as low as when the voltage-droop is deactivated (dashdotted curve) because the voltage-droop controller tries to limit the voltage drop. However, in this case the activation of the voltage-droop controller is not desired because it hampers the functioning of the frequency droop, and is solely caused by the interactions between the DC and the AC grid.

Figure 8 shows that the dual controller participates in the frequency regulation (solid curve) and stabilizes the frequency at a level above the scenario where the frequency droop is deactivated (dashed curve). However, the frequency droop is not as efficient as it is in the scenario where the voltage droop is deactivated (dashdotted curve).

In accordance with the agreement signed with the TSO, the VSC-HVDC converter must participate in the frequency regulation with a frequency droop parameter of $5 \mathrm{mHz} / \mathrm{MW}$. Because of the interaction between the two droops, the actual relation between the power deviation of the converter and the frequency deviation of the AC grid is $\frac{\Delta f_{1}}{\Delta P_{1}}=7.7 \mathrm{mHz} / \mathrm{MW}$. Hence the frequency droop does not meet the requirements agreed with the TSO and needs to be corrected.

\subsubsection{Correction of the frequency droop}

Equation (10) indicates that the relation between the AC grid's frequency and the total power deviation of converter 1 is:

$$
\Delta P_{1}=\frac{1}{k_{f_{1}}}\left(1-\frac{1}{k_{v_{1}} \sum_{j=1}^{5} \frac{1}{k_{v_{j}}}}\right) \Delta f_{1}
$$

The original engagement with the TSO was for the frequency droop to obey (12):

$$
\Delta P_{1}=\frac{1}{k_{f_{1}}} \Delta f_{1}
$$

In order to fulfil the TSO's requirements, the original frequency droop parameter $k_{f_{1}}$ must be corrected.

By replacing $k_{f_{1}}$ in (11) by the corrected value $k_{f_{1}}^{\prime}$ in (13), the effective frequency droop finally corresponds to the agreed value with the TSO.

$$
k_{f_{1}}^{\prime}=k_{f_{1}}\left(1-\frac{1}{k_{v_{1}} \sum_{j=1}^{5} \frac{1}{k_{v_{j}}}}\right)
$$

According to (13), $k_{f_{1}}$ needs to be rescaled by $1-\frac{1}{k_{v_{1}} \sum_{j=1}^{5} \frac{1}{k_{v_{j}}}}$ which corresponds to $67 \%$ of the original frequency droop parameter.

Figure 9 shows that, initially, the converter equipped with a dual controller does not meet the requirements imposed by the TSO: the dash curve does not fit the dashdotted curve. However, with the corrected value of the frequency droop, the dual controller allows the converter to fulfil the TSO's requirements (the solid curve fits the dashdotted curve) while still participating in the voltage regulation of the DC grid through an active voltage droop.

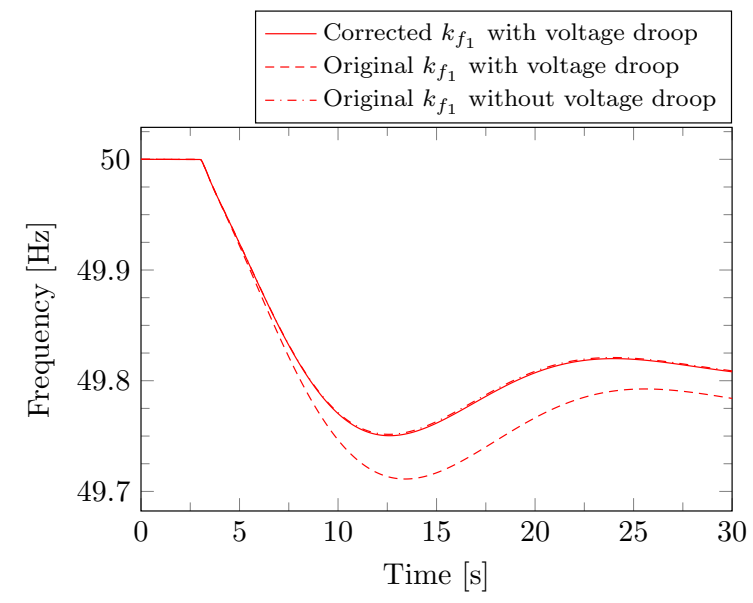

Fig. 9: Frequency of the AC grid 1

\section{Conclusions}

After reviewing the basic functioning of the voltage droop and the frequency droop for VSC-HVDC converters, this paper discussed the use of a dual controller using both droops at the same time. The coupling between the two droops was pointed out and a theoretical study showed that this coupling makes it necessary for the frequency droop parameter to be corrected in order to comply with the TSO's requirements.

Simulations using the software EMTP-RV showcases the impact of the voltage droop on the frequency droop after an AC fault and validates the corrected value of the frequency droop parameter obtained in the theoretical study, allowing the converter to comply with the TSO's exigences despite the interactions between the two droops.

The dual controller is a viable alternative to single-droop controllers since it offers the advantages of the two droops at the same time, thus a more reliable system. However, the interactions between the AC grids and the DC grid must not be overlooked since they degrades the efficiency of both droops. 


\section{References}

[1] The European Wind Energy Association, "EWEA annual report 2012," in EWEA Annual Reports, June 2013.

[2] The European Commission, "Renewable energy: Processing towards the 2020 target." Communication from the Commission to the European Parliament and the Council, January 2014.

[3] S. Akkari, M. Petit, J. Dai, and X. Guillaud, "Modélisation, simulation et commande des systèmes VSC-HVDC multi-terminaux," in Symposium de Génie Électrique (SGE14), July 2014.

[4] T. M. Haileselassie, "Control of multi-terminal VSCHVDC systems," Master's thesis, Norvegian University of Science and Technology, 2008.

[5] J. Beerten and R. Belmans, "Modeling and control of multi-terminal VSC HVDC systems," Energy Procedia, vol. 24, no. 0, pp. 123 - 130, 2012.

[6] T. Haileselassie and K. Uhlen, "Primary frequency control of remote grids connected by multi-terminal HVDC," in Power and Energy Society General Meeting, 2010 IEEE, pp. 1-6, July 2010.

[7] P. Rault, X. Guillaud, F. Colas, and S. Nguefeu, "Investigation on interactions between AC and DC grids," in PowerTech (POWERTECH), 2013 IEEE Grenoble,
pp. 1-6, June 2013.

[8] N. Chaudhuri, R. Majumder, and B. Chaudhuri, "System frequency support through multi-terminal DC (MTDC) grids," Power Systems, IEEE Transactions on, vol. 28, pp. 347-356, Feb 2013.

[9] T. K. Vrana, L. Zeni, and O. B. Fosso, "Active power control with undead-band voltage $\&$ frequency droop for HVDC converters in large meshed DC grids," in EWEA Conference, Copenhagen, 2012.

[10] P. Rault, Dynamic Modeling and Control of MultiTerminal HVDC Grids. PhD thesis, Laboratory L2EP, University Lille Nord-de-France, 2014.

[11] A. Sarlette, J. Dai, Y. Phulpin, and D. Ernst, "Cooperative frequency control with a multi-terminal high-voltage DC network," Automatica, vol. 48, no. 12, pp. 3128 - 3134, 2012 .

\section{Appendix}

DC lines specifications:

\begin{tabular}{|c|c|c|c|c|c|c|}
\hline DC line & $\mathbf{1}$ & $\mathbf{2}$ & $\mathbf{3}$ & $\mathbf{4}$ & $\mathbf{5}$ & $\mathbf{6}$ \\
\hline Length $(\mathrm{km})$ & 100 & 150 & 175 & 150 & 100 & 200 \\
\hline
\end{tabular}

DC cable resistances : $r_{l}=11 \mathrm{~m} \Omega / \mathrm{km}$
AC Overhead Lines specifications:

\begin{tabular}{|c|c|c|}
\hline AC line & $\mathbf{1}$ & $\mathbf{2}$ \\
\hline Length $(\mathrm{km})$ & 50 & 25 \\
\hline
\end{tabular}

AC OHL data:

$$
R=11.4 \mathrm{~m} \Omega / \mathrm{km} \quad L=0.936 \mathrm{mH} / \mathrm{km} \quad I_{\max }=3.5 \mathrm{kA}
$$

AC grid 1 generators power output:

\begin{tabular}{|c|c|c|}
\hline Generator & G1 & G2 \\
\hline$P_{e}(\mathrm{MW})$ & 1855 & 100 \\
\hline
\end{tabular}

AC grid 1 loads power consumption:

\begin{tabular}{|c|c|c|}
\hline Load & $\mathbf{1}$ & $\mathbf{2}$ \\
\hline Consumption (MW) & 1500 & 600 \\
\hline
\end{tabular}

Generator data:

$\begin{array}{lll}S_{N}=2000 \mathrm{MVA} & V_{N}=13.8 \mathrm{kV} & H=6.5 \mathrm{~s} \\ X_{d}=1.014 \mathrm{pu} & X_{q}=0.515 \mathrm{pu} & X_{l}=0.18 \mathrm{pu} \\ X_{d}^{\prime}=0.269 \mathrm{pu} & X_{q}^{\prime}=0.510 \mathrm{pu} & X_{0}=0.129 \mathrm{pu} \\ T_{d_{\rho}^{\prime}}^{\prime}=6.28 \mathrm{pu} & T_{q_{0}}^{\prime}=0 \mathrm{pu} & R_{a}=0.002 \mathrm{pu} \\ T_{d_{0}}^{\prime \rho}=0.08 \mathrm{pu} & T_{q_{0}}^{\prime \prime}=0.1 \mathrm{pu} & \end{array}$

Transformer data:

$V_{1 N}=13.8 \mathrm{kV}$

$V_{2 N}=320 \mathrm{kV}$

$S_{N}=2000 \mathrm{MVA}$

$R=0.0025 \mathrm{pu}$

$S_{N}=2000 \mathrm{MVA}$

